\title{
The Sounds of Intent Framework for Autism Intervention: A Conceptual Paper
}

\author{
Desiree Kaur, Aliza Alias, Maslawati Mohamad \\ Faculty of Education, National University of Malaysia, Bandar Baru Bangi, Malaysia \\ Email: hersham1984@gmail.com
}

How to cite this paper: Kaur, D., Alias, A., \& Mohamad, M. (2019). The Sounds of Intent Framework for Autism Intervention: A Conceptual Paper. Creative Education, 10, 1953-1964.

https://doi.org/10.4236/ce.2019.108141

Received: July 26, 2019

Accepted: August 23, 2019

Published: August 26, 2019

Copyright $\odot 2019$ by author(s) and Scientific Research Publishing Inc. This work is licensed under the Creative Commons Attribution International License (CC BY 4.0).

http://creativecommons.org/licenses/by/4.0/

\section{(c) (i) Open Access}

\begin{abstract}
There has been much research on the benefits of music for children with autism. The domains benefitting most from the use of music are social and communications skills. The Sounds of Intent (SoI) Framework, has been developed by Ockelford and his colleagues to promote musical abilities amongst individuals with complex needs, including autism. Underpinned by the zygonic theory, studies employed SoI also indicate increased levels of engagement among individuals with complex needs, including autism. This paper aims to provide a summary on the development of the SoI framework particularly on autistic children. Additionally, this paper includes a review of other relevant past studies on the benefits of music for children with autism on their social and communication skills. After examining the positive effects of the SoI Framework and other related past studies, the researchers intend to embark on a study using the proactive domain of the SoI framework at an autism centre in Malaysia. The researchers will employ a case study design to observe levels of musical engagement, gauge the consistency of engagement, observe the levels of prompting provided by teachers and observe challenges faced in implementing the SoI in a Malaysian special needs classroom. It is hoped that the findings could indicate that SoI would benefit children with autism, their parents and special educators and add value to existing literature on the SoI framework. Hence, the findings of this study could serve as a springboard for SoI use in Malaysia.
\end{abstract}

\section{Keywords}

Autism, Music, Sounds of Intent Framework

\section{Introduction}

The American Psychiatric Association defines Autism Spectrum Disorder or ASD as a neurodevelopmental condition characterised by challenges in social commu- 
nication, fixated interests and repetitive behaviour (Vaiouli \& Ogle, 2015). While signs of autism may be evident from as early as 6 months, the earliest diagnosis can be rendered at 18-months (Autism Speaks, 2013). There are many types of interventions to help children with autism including music.

Music and music therapy have been used with success for individuals with autism (Mossler et al., 2017; Porter et al., 2017; Schwartzberg \& Silverman, 2014; Thompson, 2017; Fong \& Jelas, 2010; Fong \& Lee, 2012; Paul, Sharda, Menon, Arora, \& Kansal, 2015; Preis, Amon, Silbert Robinette, \& Rozegar, 2016; See, 2012; Vaiouli \& Andreou, 2018; Vaiouli \& Ogle, 2015). Music therapy has been known to be effective in developing social and communication skills for individuals with autism (Mossler et al., 2017; Porter et al., 2017; Schwartzberg \& Silverman, 2014; Thompson, 2017). In addition, there is also literature to support the positive use of music as part of the intervention (Preis et al., 2016). For instance, instructions are sung rather than spoken (Paul et al., 2015).

The incorporation of music as intervention or in the classroom should not be confused with music therapy. Music therapy is a psychological clinical intervention to be delivered only by a qualified music therapist to individuals with injury, illness or disability through supporting their psychological, emotional, cognitive, physical, communicative and social needs (The British Association for Music Therapy, 2017).

Many studies have highlighted the positive effects of music on children with autism. Some of these studies employed SoI framework. Thus, the researchers have decided to employ SoI framework in the oncoming study. Hence, this conceptual paper consists of a brief overview on the development of the SoI Framework which stemmed from the Zygonic Theory. The following subsection also provides related past studies. Finally, a discussion of the intended study is also included.

\section{Literature Review}

\subsection{From the Zygonic Theory to the Sounds of Intent (SoI) Framework}

The benefits of music towards individuals with complex needs, including autism have been constantly studied. In 1983, the zygonic theory was developed. The proponents of the zygonic theory suggested that the human mind processes music and anticipates the elements of imitative melodies, rhythms and structures. According to the key proponent, Ockelford (2009), musical melodies tend to contain elements of imitation. He further claimed that, "The neo-serial and canonic techniques had a common element-imitation-and it occurred to me that when one musical feature was created by imitating another, then, to the musical mind that recognised the replication, it was as though the first metaphorically exerted some form of control over second" (Ockelford, 2009: p. 92).

Studies on zygonic theory were further extended into the area of developing individuals with complex needs, including those with autism or the possibility of displaying traits of autism (Ockelford, 2013a). Ockelford further added that music, if it is listened to often enough could be transformed into long term memory 
if the melody, lyrics and rhythm get the attention of the listener. It is due to the nature of music and the set of musical rules that are based on imitation patterns-melodic and rhythmic.

Ockelford (2009) explained that the human mind recognises music patterns of replication. Additionally, the mind processes music and anticipates elements of imitative melodies, rhythms and structures. According to Ockelford (2013a) and Ockelford (2013b), the zygonic theory can be summarised as follows:

- Musical sounds are heard as being derived through imitation. This makes music a cognitive phenomenon.

- Since the music source is an imitation, it can invoke emotions.

- Almost all humans can recognise a sense of imitation that exists in music.

- All music originates from the basis of imitation at all levels.

- Due to its imitative nature, a person does not need to hear the whole song to anticipate what it sounds like in its entirety.

- There is a relationship between music and other social activities for instances dancing and speaking.

Initially, many studies focused more on the technicalities of music and its composition from a musicology perspective. Later, studies on the zygonic theory were extended to the area of developing individuals with complex needs, including those with autism. Many researchers who applied the principles of the zygonic theory in their studies aimed to develop musical abilities among learners with complex needs (Ockelford, 2013a). Hence, a music curriculum for special education schools across England was developed based on zygonic theory (Ockelford, 2000). This resulted in other studies being embarked to create and test the SoI framework. The following paragraphs provide an explanation on how SoI framework is developed by Ockelford and his colleagues.

Ockelford, Welch, Zimmermann and Himonides (2005) has developed "The Sounds of Intent" (SoI) framework in their research. Their aim was to develop musical abilities among learners with complex needs. Since then, many researchers have employed the SoI framework to establish the relationship between music education and music therapy for learners with learning difficulties (Ockelford, Welch, \& Zimmermann, 2002; Ockelford et al., 2005; Voyajolu \& Ockelford, 2016; Vogiatzoglou, Ockelford, Welch, \& Himonides, 2011; Welch, Ockelford, Carter, Zimmermann, \& Himonides, 2009).

The following part of this paper will provide an overview of their research progression.

\subsection{The Development of the Sounds of Intent (SOI) Framework}

In 2000, Ockelford began to investigate the effects of music education towards children with complex needs. At this point of time, little was discovered on the significance of music education, in comparison to music therapy. Later, in 2002, Ockelford and his colleagues discovered that music has significant influences on people with complex needs in terms of their education and daily activities (Ockelford, Welch, \& Zimmerman, 2002). As a result, he proposed a model that con- 
sists of two strands: 1) music for pleasure; and 2) music to inform. Here, they proposed that further studies should be conducted on how children with complex needs respond to music. Based on their findings, they also proposed a new national curriculum be developed and introduced in the United Kingdom in order to meet the musical needs and abilities of individuals with complex needs.

Next, Ockelford carried out another project. In this project, he and his colleagues, divided the respondents into two groups (Ockelford et al., 2005). The first group employed the "bottom up" approach-the teachers of that centre taught the children with complex needs. The second group employed the "top-bottom" approach - the intervention was conducted by the SoI research team. Music therapists and teachers monitored the children's progress over a period of 2 years. A detailed report was documented on the children's progress. The responses from the 78 children, resulted in a multidimensional categorisation of the SoI Framework (Ockelford, 2013a) (refer to Figure 1).

Based on the responses of the children with complex needs to music, the multidimensional categorisation SoI framework was developed (Ockelford et al., 2005). As a result, three domains were introduced: 1) reactive (listening and responding to sound of music), 2) proactive (causing, creating and controlling sound-including musical sounds) and 3) interactive (participating in sound and music-making with others). Each of these 3 domains is further divided into 6 levels (refer to Figure 1).

Theoretically, learners progress according to levels and domains (refer to Figure 1). Nevertheless, there are instances which learners move between domains. For example, an individual may proceed along the levels in proactive domain progresses up to the subsequent levels and later, move into the interactive domain. The researchers that apply the SoI framework in their studies found that, while the

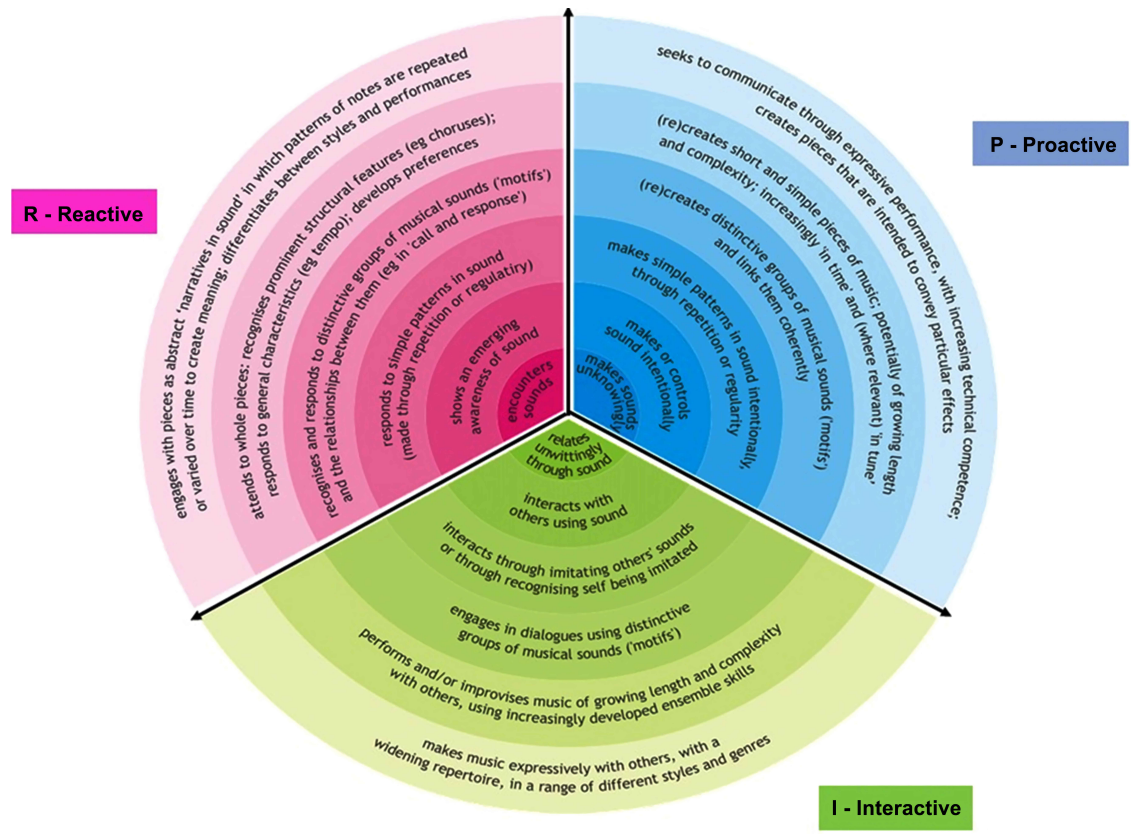

Figure 1. The sounds of intent framework. 
framework could suggest equivalence in each section, learners' levels of achievement may not necessarily be developed in symmetry. Therefore, boundaries between domains and levels still remain unclear.

Welch et al. (2009) also employed SOI framework in their study. Their findings indicate positive outcomes, thus, support the SoI framework. The findings of their study confirm Ockelford's (2008) findings-music education promotes other skills such as social, motor and communication skills among the participants (children with complex needs).

Next, in order to evaluate the achievement of each level, Ockelford et al. (2011) also outlined a protocol on a scale of 6 for musical engagement and a scale of 5 for consistency. This outline was designed based on Ockelford and his colleagues' study on 20 participants with complex needs. Their research objective was to provide a scale to other researchers who intend to apply SoI framework in their study to monitor their participants' progress. This scale is still being used until today as a part of the SoI data collection process.

In 2011, a conceptual paper was published in order to share plans to create an interactive website using the SoI framework. Vogiatzoglou et al. (2011) highlighted that this website is accessible for free on the Internet. Any users could upload their students' performances and analyse those data. The website (http://www.soundsofintent.org/) comprises information on how to use the SoI framework. According to Ockelford (2015), since its launch in 2012, the site has garnered over 4 million unique hits and 500,000 downloads by people all over the world. As SoI framework is available online, practitioners could also access to musical assessments for other activities.

Voyajolu and Ockelford (2016) also conducted a study to identify the potential of mismatches within the existing framework. They observed 58 children and young individuals with learning disabilities over a course of 6 months. They found that the initial framework is still relevant, however, it requires some updates. Even though the findings of this study enable the SoI framework to stay current and updated, Ockelford (2015) proposed that more studies be conducted to continue updating the framework. Studies using SoI framework are still progressing and their data are actively recorded via its website.

\section{The Use of Music for Children with Autism}

As mentioned in the preceding paragraphs, numerous studies on music as an intervention and music therapy for children with autism have reported positive effects in the aspects of social, communication and language skills (Mossler et al., 2017; Paul et al., 2015; Preis et al., 2016; Thompson, 2017; Vaiouli \& Andreou, 2018; Vaiouli \& Ogle, 2015). Most of these studies were conducted using qualitative approach. There were also studies conducted using mixed method approach. These studies were mainly conducted in the United States, Europe and Australia. However, such studies are still very limited in Malaysia (Fong \& Lee, 2012; Fong \& Jelas, 2010; Ong, Dani, \& Johari, 2013; See, 2012). 


\subsection{Other Related Past Studies on Using Music as an Intervention}

There are various teaching and learning methods of employing music as an intervention. Paul et al. (2015) applied a new teaching method-singing out instructions as his class activities. He made a comparison with the results of the usual spoken instructions. Their observations indicate that their participants used eye contact and social responsiveness more often when instructions were sung than spoken. Their participants were three boys with autism. However, the researchers did not study the long-term effects of the intervention.

Vaiouli and Andreau (2018) also reported positive effects of music towards children with autism. The positive effects are that the children displayed more receptive language skills through music intervention. Moreover, the children's speech production has also improved. In addition, they were more engaged in nonverbal communicative actions such as eye contact and social gestures.

Studies were also conducted on the effects of background music in structured play and therapy sessions. Schwartzberg \& Silverman (2014) and Preis et al. (2016) studied the types of background music utilised in the sessions. The studies found that frequencies of speaking (saying words or sentences) and conversations (talking with elements of turn-taking) increased with all types of music. Preis et al. (2016) found that with classical music in the background, both speaking, and conversations recorded the highest frequencies. The limitation of this study was the imbalance in terms of the types of music used in each session. Participants' profiles were not matched evenly either. Additionally, sessions were in the form of free-play with no instructions given.

Schwartzberg \& Silverman (2014) studied music therapists' reactions using various repertoires of music compared to self-composed or altered versions of songs. Questionnaires were distributed to music therapists. They answered the questionnaire based on their own methods used for students with autism. Most respondents used existing songs. However, upon further analysis, there are reasons that led the respondents to compose their own songs or change the songs' lyrics. The findings of this study can be linked to the zygonic theory. Even though the songs were altered, the melody and rhythm maintained and only the lyrics were altered. This indicates the effectiveness of familiarity in the tune, tempo and melody despite the change in lyrics. The elements of imitation coupled with familiarity of the tunes still have similar effects to the listener.

Based on the reviewed studies, the common denominator is the effectiveness of music towards improved communication and social skills. The findings of the above mentioned studies are useful to the researchers of this study as we intend to replicate some of the earlier studies. We could use the activities conducted in the previous studies to propose activities as interventions to be implemented in our classrooms.

\subsection{Related Past Studies on Music and Autism in Malaysia}

Studies on music and its effects on autism Malaysia are rather limited with only four published journal articles from 2010 to 2013. The researchers of these two 
studies (Fong \& Lee, 2012; Fong \& Jelas, 2010) used music as an intervention. Their findings indicate the success of using the intervention to improve communication skills in children with autism. The other two studies by See (2012) and Ong et al. (2013) aimed to reduce behavioural issues. See (2012) used music and movement therapy while Ong et al. (2013) used music as an auditory stimulus. All the four studies yield positive outcomes. The studies are summarised in the following (refer to Table 1).

Three of the studies in Table 1 reported positive outcomes in the students' language and communication skills. Fong and Jelas (2010) studied the effects of music education on communication skills, motor development and social skills. The positive outcomes revealed in their study were the learners' improvements on their vocal imitations, responses to speech, singing aloud and spontaneous verbal vocalisation. Later, Fong and Lee (2012) carried out a single case study. They studied the effects of music education on verbal and nonverbal interaction, singing skills and reading skills. Their study indicated positive outcomes among their participants for all three domains; communication, social and reading skills.

Using music as an auditory stimulus as well as using music and movement therapy as classroom activities also yield positive outcomes. Musical songs as an auditory stimulus are proven effective for individuals with high functioning autism, increase responsiveness in the domains of language and cognitive variables (Ong et al., 2013). Additionally, music and movement therapy has shown positive changes in behavioural issues among children with autism (See, 2012). The results of these studies indicate respondents' improvements in terms of restlessness, fidgeting, temper tantrums and attention spans.

\section{The Proposed Study}

Generally, schools for special needs in Malaysia do not provide students with much exposure to music in the classroom. For children younger than 7 , they may have slightly more exposure to songs through circle time or nursery rhyme activities. For older children who are already in government primary schools (7 years and above), their learning activities are more focused on improving learners' life skills and academics. The educators employ very little or no use of music as class activities. Since music is not a significant part of the special needs curriculum, therefore, special education teachers in Malaysia rarely receive training

Table 1. Previous research conducted in Malaysia music and its effects on learners with autism.

\begin{tabular}{ccccc}
\hline Author(s) & Year & Design & n & Focus \\
Fong \& Zalizan & 2010 & $\begin{array}{c}\text { A multiple-case-single-site } \\
\text { qualitative action research }\end{array}$ & 5 & $\begin{array}{l}\text { Documenting the effects of music sessions for } 5 \text { children with } \\
\text { high-functioning autism }\end{array}$ \\
Fong \& Lee & 2012 & Case study & 1 & Music education for communication and reading skills \\
See & 2012 & Mixed method & 41 & Music and movement therapy to change and modify behaviour \\
$\begin{array}{c}\text { Ong, Noor Aina Dani \& } \\
\text { Ahmad Zaidi Johari }\end{array}$ & 2010 & Time series & 5 & Improving inattentive behaviour with auditory stimulus \\
\hline
\end{tabular}


on music as classroom activities. Music therapy is available in Malaysia, but it is rather limited due its high cost. Thus, only affluent families could pay for the music therapy.

After reviewing the above-mentioned studies and careful consideration of the SoI domains, the researchers are proposing to observe the implementation of the proactive domain at a private autism centre in Malaysia. This study will employ a case study design (Fraenkel \& Wallen, 2009). 12 observations (twice a week over 6 consecutive weeks) will be conducted by the researchers. Each observation will take approximately 30 minutes which is their circle time. Circle time refers to the time where the teacher handles music related activities with a group of 10 children. The age range of these children is between 3 to 12 years old. The observations will be carried out to fulfill the research objectives as follows:

- To observe the levels of musical engagement and its consistency amongst children with autism using the proactive domain of the SoI framework.

- To observe levels of support provided via prompting whilst using the proactive domain of the SoI framework.

- To observe the challenges faced whilst implementing the proactive domain of the SoI framework in a Malaysian special needs classroom.

The levels of musical engagement and consistency of engagement will be recorded by the researchers using the evaluation criteria which have been set by the original SoI framework research team available at the Website. While this framework is available online for public use, the researchers have also obtained permission from the SoI research team to adapt some of the activities to suit local language and practices. The local language is Malay language and English language is the second language. Most of the songs are delivered in two languages as the children are bilinguals namely Malay and English. Malay language is the language of instruction in Malaysia. Malaysia is a multiracial country with major races which are Chinese, Indian and Malay. Thus, most Malaysians are multilingual.

Special education teachers in Malaysia are from diverse cultural backgrounds or different races namely Chinese, Malay and Indians. Due to the varied background and levels of musical understanding, the SoI framework seems to be quite complex for them to understand fully. In order to aid the teachers' understanding, the researchers will provide a guideline for the teachers. Training to use the guideline is not necessary because it only contains the additional 5 types of percussion instruments to be played by the children monitored by the teacher. The teachers and their children will adhere to the guidelines in conducting the activities. The teachers will use nursery rhymes and percussion instruments. The researchers will also make minor changes to the lyrics however the melody and rhythm of the nursery rhymes will remain in order to retain a sense of familiarity among the children. The researchers will also seek 3 experts' opinions on the selected activities to ensure their feasibility. One of the experts is a Malaysian qualified music therapy with over than 10 years working experience in the field 
and also familiar with the framework. Her familiarity is due to her United Kingdom (UK) academic background and she is also practicing music therapy in Malaysia. Another expert is Special Education lecturer who served more than 20 years in a public university in Malaysia. The third expert is a teacher with more than 5 years working experience working with autistic children ( $3-10$ years old). This is to ensure the feasibility, practicality and applicability of the researchers' proposed activities in the context of Malaysian culture, local language and school systems which differ from the UK.

Voyajolu \& Ockelford (2016) pointed out in their article that more research is required on the influence of adult support in the musical engagement. Hence, this study will also observe levels of support provided by the teachers using the prompting technique whilst music activities are conducted during "circle time". The researchers will observe the frequency of prompting using a tracking sheet which will be validated by the abovementioned three experts.

Since there are still very limited local studies using the SoI framework for children with autism in local context, the researchers will also observe any challenges faced by the teachers and children in implementing the proposed activities as part of the proactive domain. The observation notes will be further verified and triangulated by conducting individual interviews with the teachers involved in the implementation of the proactive domain. Individual interview is more suitable to avoid any disagreements among themselves when expressing their opinions. After six weeks of observations, the selected teachers will be interviewed. The selected four teachers are those who will be involved in the circle time activities. They will be interviewed via face-to-face by the researchers using a validated interview protocol by the same experts (Bhattacherjee, 2012; Creswell, 2012). Each respondent will be interviewed once and each interview will take approximately 60 to 90 minutes. The interviews will be conducted in the centre. The transcription of the interview responses will be returned to the respondents to check the accuracy. The responses will be transcribed verbatim.

\section{Student Participant Selection and Research Ethics}

Participants' selection will be based on purposive sampling (Fraenkel \& Wallen, 2009). The participants will be selected based on the following criteria:

- children with an official diagnosis of autism by a qualified specialist,

- aged between 3 to 10 and have enrolled at the private autism centre,

- parents' willingness for their child to participate in the study.

The autism centre selected for this study required each student to produce a letter or documentation from a specialist prior to enrolment. Hence, all the students enrolled at the selected school meet with this criterion. Most SoI studies were conducted with children aged 0 to 5 years. However, these studies incorporated a larger population of special needs besides autism. This proposed study focuses only on children with autism which can only be diagnosed at 18-months onwards (Autism Speaks, 2013). Furthermore, special needs private centres in 
Malaysia only accept students from the age of 3 years old. Younger children are encouraged to undergo Occupational Therapy in preparation for daily school or early intervention programmes.

Parents' consent and willingness for their children to participate is the key to participants' selection. The researchers will video record all activities conducted whereby some of these videos will be uploaded to the SoI Website. As such, after selecting the target participants, the researchers will issue letters to the parents to obtain written consent for their child to participate in this study.

\section{Conclusion}

There are many studies on music as well as music therapy on individuals with autism, with successful outcomes. Most of the studies reported positive outcomes in the areas of social skills (Paul et al., 2015; Preis et al., 2016; Thompson, 2017; Vaiouli \& Ogle, 2015), as well as language and communication skills (Mossler et al., 2017; Thompson, 2017; Vaiouli \& Andreou, 2018). Nevertheless, Malaysian based studies are still very limited (Kaur et al., 2015). Hence, the researchers intend to embark on this study.

The findings of this study could shed some light on effective music activities for children with autism. It is hoped that with some published findings on the use of the SoI framework in Malaysia, it could create an avenue for local special educators to consider the integration of music as their classroom activities. These findings could assist special educators to employ a more purposeful use of music and musical instruments as the classroom activities when engaging their students.

The data gathered in this study will be updated in the SoI website. Most of its findings thus far focus on special needs in general-incorporating severe and multiple disabilities. There is limited literature focusing specifically on autism. It is hoped that this study could shed some light on the effectiveness of the framework for children with autism.

Lastly, adult support in implementing the SoI is suggested as an area of future research (Voyajolu \& Ockelford, 2016). Hence, it is hoped that these findings could add value to existing literature of the SoI framework ongoing research.

\section{Conflicts of Interest}

The authors declare no conflicts of interest regarding the publication of this paper.

\section{References}

Autism Speaks (2013). How Early Can Autism Be Diagnosed? New York: Autism Speaks Inc.

https://www.autismspeaks.org/expert-opinion/how-early-can-autism-be-diagnosed

Bhattacherjee, A. (2012). Social Science Research: Principals, Methods and Practices. Textbook Collection 3. University of South Florida Open Access Library.

Creswell, J. (2012). Educational Research: Planning, Conducting, and Evaluating Quan- 
titative and Qualitative Research (4th ed.). Needham Heights: Pearson

Fong, C. E., \& Jelas, Z.M. (2010). Music Education for Children with Autism in Malaysia. Procedia-Social and Behavioral Sciences, 9, 70-75.

Fong, C. E., \& Lee, C. S. (2012). Communication Responses of an Indian Student with Autism to Music Education. Procedia-Social and Behavioral Sciences, 65, 808-814. https://doi.org/10.1016/j.sbspro.2012.11.203

Fraenkel, J. R., \& Wallen, N. E. (2009). How to Design and Evaluate Research in Education (7th ed.). New York: McGraw-Hill Higher Education.

Kaur, J., Engkasan, J. P., Sivanesom, R. S., Bahar, N. H., Noorand, M. M., \& Kamarudin, K. N. (2015). Technical Report Autism Spectrum Disorder Research in Malaysia. Malaysia: Ministry of Health Malaysia.

Mossler, K., Gold, C., Aßmus, J., Schumacher, K., Calvet, C., Reimer, S., Iversen, G., \& Schmid, W. (2017). The Therapeutic Relationship as Predictor of Change in Music Therapy with Young Children with Autism Spectrum Disorder. Journal of Autism and Developmental Disorders, 49, 2795-2809.

Ockelford, A, (2008). Music for Children and Young People with Complex Need. Oxford: Oxford University Press.

Ockelford, A. (2000). Music in the Education of Children with Severe or Profound Learning Difficulties: Issues in Current U.K. Provision, a New Conceptual Framework, and Proposal for Research. Psychology of Music, 28, 197-217.

https://doi.org/10.1177/0305735600282009

Ockelford, A. (2009). Zygonic Theory: Introduction, Scope and Prospects. GMTH Proceedings, 6, 91-172. https://doi.org/10.31751/400

Ockelford, A. (2013a). Applied Musicology. Using Zygonic Theory to Inform Music Education, Therapy, and Psychology Research. Oxford: Oxford University Press.

Ockelford, A. (2013b). Music, Language and Autism. Exceptional Strategies for Exceptional Minds. London: Jessica Kingsley Publishers.

Ockelford, A. (2015). The Sounds of Intent Project: Modelling Musical Development in Children with Learning Difficulties. Tizard Learning Disability Review, 20, 179-194. https://doi.org/10.1108/TLDR-02-2015-0007

Ockelford, A., Welch, G., \& Zimmermann, S. (2002). Focus of practice: Music Education for Pupils with Severe or Profound and Multiple Difficulties-Current Provision and Future Need. British Journal of Special Education, 29, 178-182. https://doi.org/10.1111/1467-8527.00266

Ockelford, A., Welch, G., Jewell-Gore, L., Cheng, E., Vogiatzoglou, A., \& Himonides, E. (2011). Sounds of Intent, Phase 2: Gauging the Music Development of Children with Complex Needs. European Journal of Special Needs Education, 26, 177-199. https://doi.org/10.1080/08856257.2011.563606

Ockelford, A., Welch, G., Zimmermann, S., \& Himonides, E. (2005). "Sounds of Intent": Mapping, Assessing and Promoting the Musical Development of Children with Profound and Multiple Learning Difficulties. International Congress Series, 1282, 898-902. https://doi.org/10.1016/j.ics.2005.04.007

Ong, J. H. L., Dani, N. A., \& Johari, A. Z. (2013). Auditory Stimulus for Children With High Functioning Autism : Towards Reducing Developmental Disorders and Inattentive Attitudes. BJ Kines-National Journal of Basic \& Applied Sciences, 7, 676-682.

Paul, A., Sharda, M., Menon, S., Arora, I., \& Kansal, N. (2015). Responsiveness in Children with Autism Spectrum Disorders. Frontiers in Human Neuroscience, 9, 555. https://doi.org/10.3389/fnhum.2015.00555 
Porter, S., McConnell, T., McLaughlin, K., Lynn, F., Cardwell, C., Braiden, H. J., Boylan, J. et al. (2017). Music Therapy for Children and Adolescents with Behavioural and Emotional Problems: A Randomised Controlled Trial. Journal of Child Psychology and Psychiatry and Allied Disciplines, 58, 586-594. https://doi.org/10.1111/jcpp.12656

Preis, J., Amon, R., Silbert Robinette, D., \& Rozegar, A. (2016). Does Music Matter? The Effects of Background Music on Verbal Expression and Engagement in Children with Autism Spectrum Disorders. Music Therapy Perspectives, 34, 106-115. https://doi.org/10.1093/mtp/miu044

Schwartzberg, E. T., \& Silverman, M. J. (2014). Music Therapy Song Repertoire for Children with Autism Spectrum Disorder: A Descriptive Analysis by Treatment Areas, Song Types, and Presentation Styles. The Arts in Psychotherapy, 41, 240-249. https://doi.org/10.1016/j.aip.2014.03.007

See, C. M. (2012). The Use of Music and Movement Therapy to Modify Behaviour of Children with Autism. Pertanika Journals of Social Sciences and Humanities, 20, 1103-1116.

The British Association for Music Therapy (2017). What Is Music Therapy? https://www.bamt.org/music-therapy/what-is-music-therapy.html

Thompson, G. A. (2017). Long-Term Perspectives of Family Quality of Life Following Music Therapy with Young Children on the Autism Spectrum: A Phenomenological Study. Journal of Music Therapy, 54, 432-459. https://doi.org/10.1093/jmt/thx013

Vaiouli, P., \& Andreou, G. (2018). Communication and Language Development of Young Children with Autism: A Review of Research in Music. Communication Disorders Quarterly, 39, 323-329. https://doi.org/10.1177/1525740117705117

Vaiouli, P., \& Ogle, L. (2015). Music Strategies to Promote Engagement and Academic Growth of Young Children with ASD in the Inclusive Classroom. Young Exceptional Children, 18, 19-28. https://doi.org/10.1177/1096250614523968

Vogiatzoglou, A., Ockelford, A., Welch, G., \& Himonides, E. (2011). Sounds of Intent: Interactive Software to Assess the Musical Development of Children and Young People with Complex Needs. Music \& Medicine, 3, 189-195.

Voyajolu, A., \& Ockelford, A. (2016). Sounds of Intent in the Early Years: A Proposed Framework of Young Children's Musical Development. Research Studies in Music Education, 38, 93-113. https://doi.org/10.1177/1321103X16642632

Welch, G., Ockelford, A., Carter, F. C., Zimmermann, S. A., \& Himonides, E. (2009). "Sounds of Intent": Mapping Musical Behaviour and Development in Children and Young People with Complex Needs. Psychology of Music, 37, 348-370.

https://doi.org/10.1177/0305735608099688 